\title{
Factors Associated with Skin Cancers in People with Albinism in Togo
}

\author{
Abas Mouhari-Toure, ${ }^{1}$ Sefako Abla Akakpo, ${ }^{2}$ Julienne Noude Teclessou, ${ }^{3}$ Piham Gnossike, ${ }^{4}$ \\ Saliou Adam, ${ }^{5}$ Garba Mahamadou, ${ }^{2}$ Panawé Kassang, ${ }^{2}$ Yvette Elegbede, ${ }^{6}$ Tchin Darre, ${ }^{7}$ \\ Koussake Kombate, ${ }^{3}$ Palokinam Pitché, ${ }^{2}$ and Bayaki Saka $\mathbb{D}^{2}$
}

\author{
${ }^{1}$ Service de Dermatolgie et IST, CHU Kara, Université de Kara, Kara, Togo \\ ${ }^{2}$ Service de Dermatolgie et IST, CHU Sylvanus Olympio, Université de Lomé, Lomé, Togo \\ ${ }^{3}$ Service de Dermatolgie et IST, CHU Campus Université de Lomé, Lomé, Togo \\ ${ }^{4}$ Centre National de Dermatologie de Gbossimé, Lomé, Togo \\ ${ }^{5}$ Service de Chirurgie Maxillo-faciale et Plastique, CHU Sylvanus Olympio, Université de Lomé, Lomé, Togo \\ ${ }^{6}$ Service de Dermatolgie et IST, Centre Hospitalier Régional de Tomdè, Kara, Togo \\ ${ }^{7}$ Laboratoire D'anatomie et Cytotologie Pathologique, CHU Sylvanus Olympio, Université de Lomé, Lomé, Togo
}

Correspondence should be addressed to Bayaki Saka; barthelemysaka@yahoo.fr

Received 25 November 2021; Accepted 17 December 2021; Published 23 December 2021

Academic Editor: Arash Kimyai Asadi

Copyright (C) 2021 Abas Mouhari-Toure et al. This is an open access article distributed under the Creative Commons Attribution License, which permits unrestricted use, distribution, and reproduction in any medium, provided the original work is properly cited.

Objective. The aim of this study was to identify the factors associated with skin cancers in people with albinism (PWA) in Togo. Method. This is a retrospective analytical study of the records of PWA examined during five dermatological consultation campaigns from 2019 to 2021. Results. During the study period, 517 PWA were seen. Sixty-four (12.3\%) of these PWA had presented with 137 cases of skin cancer. The sex ratio (M/F) was 0.9. The average age of PWA with skin cancer was $39.69 \pm 15.61$ years and that of PWA without skin cancer was $19.17 \pm 15.24$ years $(p \leq 0.001)$. The 137 cases of skin cancers were dominated by basal cell carcinomas (45.9\%). These skin cancers were located preferentially in the cephalic region (77 cases; $56.2 \%)$, followed by the upper limbs (33 cases; 24.1\%). In multivariate analysis, the risk factors for skin cancers in PWA were age over 39 years $(p \leq 0.001)$ and the presence of actinic keratoses $(p \leq 0.001)$. In contrast, the presence of ephelides $(p=0.018)$ was a protective factor. Conclusion. This study confirms that advanced age and actinic keratoses are risk factors for skin cancer in PWA, in connection with the cumulative role of solar radiation. Its originality lies in the identification of ephelides as a protective factor. The knowledge and consideration of these risk factors will make it possible to optimise strategies for the prevention of skin cancers in PWA.

\section{Introduction}

Oculocutaneous albinism (OCA) is an inherited condition caused by a deficiency or absence of tyrosinase activity, a key enzyme in melanin biosynthesis by melanocytes in the skin, hair follicles, and eyes $[1,2]$. Because of the reduction or absence of melanin, PWA are very sensitive to the harmful effects of ultraviolet (UV) light. They are more at risk of actinic lesions and dermatoses, the most worrying of which are precancerous and cancerous lesions [3].
Epidemiologically, OCA is a universal and ubiquitous condition affecting approximately $1 / 17,000$ people worldwide regardless of race or gender [4]. In sub-Saharan Africa, it is about $1 / 5000$ people [5]. African PWA are more prone to skin cancers because they live near the equator where exposure to the Sun's UV rays is very high [6]. According to the United Nations, $98 \%$ of PWA do not live beyond the age of 40 because of sun exposure, with skin cancers accounting for at least $80 \%$ of their deaths [5]. The majority of these skin cancers are represented by squamous cell carcinoma (SCC) 
in $75-88 \%$, basal cell carcinoma (BCC) in $9-23 \%$, and melanoma in rare cases (1.3-3\%) [7]. Genetic (phototypes) and environmental (sun exposure) factors have been implicated in the occurrence of non-melanoma skin cancers $[8,9]$.

Some studies have reportedly shown a correlation between the presence of ephelides and the age of PWA $[10,11]$. Studies conducted in Africa on PWA are mostly descriptive, as in Togo $[12,13]$. We are conducting this study to identify the risk factors associated with skin cancers in PWA in Togo, in order to propose adequate preventive measures.

\section{Method}

This is a retrospective analytical study of the files of PWA examined during five dermatological consultation campaigns from 2019 to 2021, as part of a programme for the prevention and management of skin cancers in these subjects. For each campaign, there was a coordination team from the National Association of People with Albinism in Togo (ANAT) and a medical team made up of dermatologists proposed by the Togolese Society of Dermatology and Sexually Transmitted Infections (SOTODERM), a maxillofacial surgeon, and the ANAT health manager. The number of dermatologists during these campaigns varied depending on whether one was in the capital Lomé ( 2 to 3 dermatologists for three days) or in a town in the interior (one dermatologist for 2 days in Atakpamé and one dermatologist for one day in the rest of the towns visited). The diagnosis of albinism was exclusively clinical, based on the colour of the skin and hair (generalized hypopigmentation of the skin and hair) and the presence of nystagmus. During these campaigns, when a lesion was suspected of being cancerous, a biopsy or biopsy-exeresis was performed and sent to the pathological anatomy laboratory of the Mélia clinic or the CHU Sylvanus Olympio. For each PWA, the data collected were sociodemographic (age, sex, and place of residence), clinical, and histological (precancerous lesions, existence and type of skin cancers, localization, and histology results).

2.1. Data Processing and Statistical Analysis. The questionnaires were entered using CS software version 7.6. The entered data were then exported to a database in Excel format. Descriptive analyses were carried out, and the results were presented in the form of graphs, tables, frequencies, and percentages. Quantitative variables were described by means ( \pm standard deviation), and qualitative variables were described by frequencies and percentages. A bivariate analysis was performed. Quantitative variables were compared by Student's $t$-test, and qualitative variables were compared by the chi ${ }^{2}$ test. Variables that were associated with skin cancer risk factors (probability values less than 0.25 ) were retained for multivariate analysis. The multivariate analysis was therefore performed for variables significantly associated with skin cancers. The results expressed as odds ratio (OR) were given with a $95 \%$ confidence interval. All analyses were performed using R๑ version 3.3.2 software.

\section{Results}

During the 5 campaigns, 517 PWA were consulted at least once, of which $64(12.4 \%)$ had presented with 137 cases of skin cancer (the number of skin cancers varied from 1 to 10 in one patient). The mean age of the PWA was $21.7 \pm 16.7$ years (range: 1 and 90 years) with a sex ratio (M/F) of 0.9 . PWA with skin cancer had a mean age of $39.7 \pm 15.6$ years, and PWA without skin cancer had a mean age of $19.2 \pm 15.2$ years $(p \leq 0.001)$. A family history of albinism was found in 196 PWA (37.9\%), and consanguinity was reported in 85 PWA (16.4\%). The PWA were more likely to live in urban areas $(78.9 \%)$.

The majority of PWA $(n=399 ; 77.2 \%)$ had freckles (ephelides), followed by actinic keratoses $(n=298 ; 57.6 \%)$, actinic cheilitis $(n=239 ; 46.2 \%)$, and elastosis $(n=4 ; 0.8 \%)$. The 137 cases of skin cancer were dominated by BCC $(n=63$; $45.9 \%$ ) (a patient could have several cases and histological types of skin cancer) (Table 1$)$. The skin cancers were located in the cephalic region $(n=77 ; 56.2 \%)$, followed by the upper limbs $(n=33 ; 24.1 \%)$, trunk $(n=21 ; 15.3 \%)$, and lower limbs $(n=6 ; 4.4 \%)$. In univariate analysis, age above 39 years, the existence of ephelides, and actinic keratoses were associated with the risk of skin cancer (Table 2). In multivariate analysis, the risk factors for skin cancers in PWA were age over 39 years $(p \leq 0.001)$ and the presence of actinic keratoses $(p \leq 0.001)$. In contrast, the presence of ephelides $(p=0.018)$ was a protective factor (Table 3$)$.

\section{Discussion}

In our study, the prevalence of skin cancer was $12.4 \%$. To our knowledge, no work has documented the incidence or the prevalence of skin cancers in the non-albino population in Togo for comparison with the albino one. This prevalence (12.4\%) is lower than the 26\% reported in Brazil [14], 25\% in Tanzania [15], 23\% in South Africa [10], and 20.9\% in Nigeria [16] but higher than $4.6 \%$ reported in France [17]. Our low rate can be explained by the absence of some PWA during the campaigns because they live in very remote areas that have not been affected by these activities and have no access to health centres. The mobile consultation strategy is certainly the one we used during the campaigns, but our consultations mainly reach PWA in urban areas. Furthermore, PWA are the target of prejudice and social exclusion, which would prevent them from having easy access to health care and information about mobile consultations [14, 18].

The average age of onset of skin cancer in PWA in our series was 39.5 years, lower than that of the general Togolese population (42 years) [19]. PWA develop solar radiation-related diseases earlier because of the lack of sun protection from a young age, and cancerous tumours occur from the second decade of their lives $[4,20]$. This cumulative role of solar radiation also explains the fact that the average age of PWA with skin cancer was significantly higher than that of PWA without skin cancer in our study. Thus, photoprotection remains a challenge from the young age of PWA, especially as the dress code is light due to the hot climate. 
TABLE 1: Frequency of the main skin cancers.

\begin{tabular}{lcc}
\hline & Number & $\%$ \\
\hline Basal cell carcinoma & 63 & 45.9 \\
Squamous cell carcinoma & 55 & 40.1 \\
Bowen disease & 12 & 8.8 \\
Malignant melanoma & 2 & 1.5 \\
Paget's disease & 2 & 1.5 \\
Malignant lymphoma & 3 & 2.2 \\
Total & 137 & 100 \\
\hline
\end{tabular}

TABLE 2: Factors associated with skin cancer in univariate analysis.

\begin{tabular}{|c|c|c|c|c|}
\hline & $\begin{array}{l}\text { PWA without skin cancer } \\
\qquad N=453\end{array}$ & $\begin{array}{l}\text { PWA with skin cancer } \\
\qquad N=64\end{array}$ & $\begin{array}{c}\text { Total } \\
N=517\end{array}$ & $p$ value \\
\hline \multicolumn{5}{|l|}{ Age (years) } \\
\hline Mean (standard deviation) & $19.2( \pm 15.2)$ & $39.7( \pm 15.7)$ & & $\leq 0.001$ \\
\hline$>39, n(\%)$ & $45(58.4)$ & $32(41.6)$ & 77 & \\
\hline$\leq 39, n(\%)$ & $408(92.7)$ & $32(7.3)$ & 440 & $\leq 0.001$ \\
\hline Sex & & & & 0.989 \\
\hline Female, $n(\%)$ & $234(87.6)$ & $33(12.4)$ & 267 & \\
\hline Male, $n(\%)$ & $219(87.6)$ & $31(12.4)$ & 250 & \\
\hline Area of residence & & & & 0.071 \\
\hline Rural, $n(\%)$ & $90(82.6)$ & $19(17.4)$ & 109 & \\
\hline Urban, $n(\%)$ & $363(89.0)$ & $45(11.0)$ & 408 & \\
\hline Presence of ephelides & & & & 0.042 \\
\hline No & $97(82.2)$ & $21(17.8)$ & 118 & \\
\hline Yes & $356(89.2)$ & $43(10.8)$ & 399 & \\
\hline Presence of elastosis & & & & 0.450 \\
\hline No & $449(87.5)$ & $64(12.5)$ & 513 & \\
\hline Yes & $4(100.0)$ & $0(0.0)$ & 4 & \\
\hline Presence actinic keratosis & & & & $\leq 0.001$ \\
\hline No & $210(95.9)$ & $9(4.1)$ & 219 & \\
\hline Yes & $243(81.5)$ & $55(18.5)$ & 298 & \\
\hline
\end{tabular}

TABLE 3: Risk factors associated with skin cancer in PWA (multivariate analysis).

\begin{tabular}{lccc}
\hline Variables & aOR & IC95\% & $p$ value \\
\hline $\begin{array}{l}\text { Age (years) } \\
\quad 39\end{array}$ & 1.000 & - & - \\
$\quad \leq 39$ & 0.163 & $0.09-0.3$ & $\leq 0.001$ \\
$\quad$ Area of residence & & & \\
$\quad$ Urban & 1.000 & - & - \\
$\quad$ Rural & 1.598 & $0.84-3.04$ & 0.063 \\
Presence of ephelides & & & \\
$\quad$ No & 1.000 & - & - \\
$\quad$ Yes & 0.462 & $0.24-0.88$ & 0.018 \\
Presence of actinic keratosis & & & \\
$\quad$ No & 1.000 & - & - \\
$\quad$ Yes & 4.321 & $2.11-8.87$ & $\leq 0.001$ \\
\hline
\end{tabular}

We counted 137 cases of skin cancers dominated by basal cell carcinomas. The predominance of BCC could therefore be explained by the fact that our screening was active during the campaigns, with biopsy of all suspected lesions, even asymptomatic ones. In Nigeria [16], BCC was also the most frequent skin carcinoma (55\%), followed by SCC (22\%). In addition to cutaneous carcinoma, we found cases of melanoma, lymphoma, and Paget's disease, which we did not find in 2019 [13], probably due to the limited number of patients.

In our study, the risk factors for skin cancer in PWA were age above 39 years $(p \leq 0.001)$ and the presence of actinic keratoses $(p \leq 0.001)$, which is related to the cumulative role of solar radiation. In contrast, the presence of ephelides $(p=0.018)$ was a protective factor.

Regarding age, PWA aged 39 years and over were the most represented among those with skin cancers. Indeed, the risk of developing skin cancer in PWA was multiplied by 6.32 as age increased. This finding was also made in the Brazilian series which also highlighted the influence of age in the occurrence of skin cancer in PWA [14]. The main reason would be the effect of early skin ageing due to cumulative exposure to solar radiation. For technical reasons (unavailability of photobiology), we could not quantify this UV exposure in our PWA.

Secondly, the presence of actinic keratoses multiplies the risk of developing skin cancer in PWA by 4.639. The presence of actinic keratoses has already been found to be a risk factor associated with the occurrence of skin cancers in the Brazilian study [14]. Actinic keratoses are in fact 
precancerous lesions, and some of them are even carcinomas in situ.

Furthermore, the presence of ephelides reduces the risk of developing skin cancer by more than 1.63 times. This finding of a protective factor for ephelides was made by Kromberg et al. [10] but is difficult to interpret.

\section{Limitations of the Study}

The main strength of our study is that it is the doctors who travel to the populations, which solves some of the problems that are limitations of hospital-based studies, notably geographical inaccessibility and lack of financial means to consult. Its main limitation was its retrospective nature and the sincerity of the information collected from the PWA during the campaigns.

\section{Conclusion}

This study confirms that advanced age and actinic keratoses are risk factors for skin cancer in PWA, in connection with the cumulative role of solar radiation. Its originality lies in the identification of ephelides as a protective factor. The knowledge and consideration of these risk factors will make it possible to optimise strategies for the prevention of skin cancers in PWA.

\section{Abbreviations}

$\begin{array}{ll}\text { ANAT: } & \text { National Association of Albinos of Togo } \\ \text { BCC: } & \text { Basal cell carcinoma } \\ \text { PWA: } & \text { Patients with albinism } \\ \text { SCC: } & \text { Squamous cell carcinoma } \\ \text { SOTODERM: } & \text { Togolese Society of Dermatology and } \\ & \text { Sexually Transmitted Infections } \\ \text { UV: } & \text { Ultraviolet. }\end{array}$

\section{Data Availability}

The data used to support the findings of this study are available from the corresponding author upon request.

\section{Ethical Approval}

This study was approved by the comite de biothétique pour la recherche en santé (Ref no. 015/2019/CBRS).

\section{Consent}

We obtained consent from PWA that participated in the study. For each person with albinism, the objectives and benefits of participating in the survey and its conduct were clearly stated as well as their right to interrupt the interview without justification. An informed consent form signed after the verbal explanation was made by the investigating officer in the language understood by the participant.

\section{Conflicts of Interest}

The authors declare that they have no conflicts of interest.

\section{Authors' Contributions}

AM, BS, PP, and GM were responsible for the conception of the study, participated in the study design, undertook the field study, conducted the data collection, analysis, and interpretation, and wrote, revised, and finalized the manuscript. PK, SA, JT, SAK, PG, and YE were involved in the data collection, analysis, and interpretation and wrote and finalized the manuscript. AM, TD, and KK were involved in data analysis and interpretation and revised and finalized the manuscript. All the authors were responsible for the overall scientific management of the study, analysis and interpretation, and preparation of the final manuscript. Finally, all the authors read and approved the final manuscript to be submitted for publication.

\section{Acknowledgments}

We would like to thank the Pierre Fabre Foundation for fully funding this dermatological consultation project for people with albinism (PWA) in Togo. We also thank the National Association of Albinos of Togo (ANAT) for coordinating the PWA mobile clinics in Togo in 2019.

\section{References}

[1] J. Okulicz, R. Shah, R. Schwartz, and C. Janniger, "Oculocutaneous albinism," Journal of the European Academy of Dermatology and Venereology, vol. 17, no. 3, pp. 251-256, 2003.

[2] J. Bolognia, J. Jorizzo, and J. Schaffer, Dermatology, Saunders Elsevier, Philadelphia, PA, USA, 3rd edition, 2012.

[3] K. Grønskov, J. Ek, and K. Brondum-Nielsen, "Oculocutaneous albinism," Orphanet Journal of Rare Diseases, vol. 2, p. 43, 2007.

[4] B. Arveiller, E. Lasseaux, and F. Maurice-Picard, "Clinique et génétique de l'albinisme," La Presse Médicale, vol. 46, no. 7-8, pp. 648-654, 2017.

[5] E. Nakkazi, "People with albinism in Africa: contending with skin cancer," The Lancet, vol. 394, no. 10198, pp. 553-554, 2019.

[6] O. Awe and T. Azeke, "Cutaneous cancers in Nigerian albinos: a review of 22 cases," Nigerian Journal of Surgery, vol. 24, no. 1, pp. 34-38, 2018.

[7] S. Ozaki, Y. Funasaka, Y. Otsuka et al., "Melanotic malignant melanoma in oculocutaneous albinism type 4," Acta DermatoVenereologica, vol. 97, no. 2, pp. 287-288, 2017.

[8] H. Baskurt, E. Celik, G. Yesiladali, and M. Tercan, "Importance of hereditary factors in synchronous development of basal cell carcinoma in two albino brothers: case report," Annals of Plastic Surgery, vol. 66, no. 6, pp. 640-642, 2011.

[9] C. Y. Wright, D. J. du Preez, D. A. Millar, and M. Norval, "The epidemiology of skin cancer and public health strategies for its prevention in southern Africa," International Journal of Environmental Research and Public Health, vol. 17, no. 3, Article ID 1017, 2020.

[10] J. G. Kromberg, D. Castle, E. M. Zwane, and T. Jenkins, "Albinism and skin cancer in southern Africa," Clinical Genetics, vol. 36, pp. 43-52, 1989.

[11] R. Aquaron, J. L. Berge-Lefranc, E. Lassaux, C. Plaisant, B. Arveiller, and M. Brilliant, "What can we learn from the distribution of the $2.7 \mathrm{~kb}$ deletion mutation of the OCA2 gene 
in oculocutaneous albinism type 2 (OCA2) in Cameroun and in Sub-Saharan Countries," JSM Dermatology and Clinical Research, vol. 5, pp. 1-5, 2019.

[12] B. Saka, J. N. Teclessou, S. A. Akakpo et al., "A histopathological study of skin lesions in individuals with oculocutaneous albinism in Togo in 2019," Journal of Skin Cancer, vol. 2020, Article ID 2361957, 4 pages, 2020.

[13] B. Saka, S. A. Akakpo, J. N. Teclessou et al., "Skin cancers in people with albinism in Togo in 2019: results of two rounds of national mobile skin care clinics," BMC Cancer, vol. 21, no. 1, p. 26, 2021.

[14] C. R. Marçon, J. C. Moraes, M. A. M. de Olivas Ferreira, and C. B. Oliari, "Dermatological and epidemiological profiles of patients with albinism in São Paulo, Brazil, between 2010 and 2017: a cross-sectional study," Dermatology, vol. 236, no. 3, pp. 219-227, 2019.

[15] D. P. Lookingbill, G. L. Lookingbill, and B. Leppard, “Actinic damage and skin cancer in albinos in northern Tanzania: findings in 164 patients enrolled in an outreach skin care program," Journal of the American Academy of Dermatology, vol. 32, no. 4, pp. 653-658, 1995.

[16] N. A. Enechukwu, G. O. Ogun, O. I. Ezejiofor et al., "Histopathologic patterns of cutaneous malignancies in individuals with oculocutaneous albinism in Anambra state, Nigeria: a paradigm swing?" Ecancermedicalscience, vol. 14, Article ID 1013, 2020.

[17] J. F. Gamella, E. M. Carrasco-Muñoz, and A. M. Núñez Negrillo, "Oculocutaneous albinism and consanguineous marriage among Spanish Gitanos or Calé--a study of 83 cases," Collegium Antropologicum, vol. 37, no. 3, pp. 723-734, 2013.

[18] A. E. Cruz-Inigo, B. Ladizinski, and A. Sethi, "Albinism in Africa: stigma, slaughter and awareness campaigns," Dermatologic Clinics, vol. 29, no. 1, pp. 79-87, 2011.

[19] B. Saka, Z. Souley, K. Kombaté et al., "Skin cancers in Togo: a 223-case series," Journal of Tropical Medicine, vol. 70, no. 2, pp. 169-171, 2010.

[20] S. K. Kiprono, B. M. Chaula, and H. Beltraminelli, "Histological review of skin cancers in African Albinos: a 10-year retrospective review," BMC Cancer, vol. 14, no. 1, p. 157, 2014. 